\title{
Enzymatic Browning, Polyphenol Oxidase Activity, and Polyphenols in Four Apple Cultivars: Dynamics during Fruit Development
}

\author{
Daniel Ferreira Holderbaum \\ Plant Developmental Physiology and Genetics Laboratory, Agricultural \\ Sciences Center, Federal University of Santa Catarina, Rodovia Admar \\ Gonzaga 1346, Florianópolis-SC, 88034-001, Brazil
}

\section{Tomoyuki Kon}

Aomori Apple Institute, Aomori Prefecture Industrial Technology Research Center, 24 Aza-Fukutami, Oaza-Botandaira, Kuroishi, Aomori, Japan

\section{Tsuyoshi Kudo}

Aomori Apple Institute, Aomori Prefecture Industrial Technology Research Center, 24 Aza-Fukutami, Oaza-Botandaira, Kuroishi, Aomori, Japan

\section{Miguel Pedro Guerra ${ }^{1}$}

Plant Developmental Physiology and Genetics Laboratory, Agricultural Sciences Center, Federal University of Santa Catarina, Rodovia Admar Gonzaga 1346, Florianópolis-SC, 88034-001, Brazil

Additional index words. Malus $\times$ sylvestris var. domestica, fruit maturation, polyphenolspolyphenol oxidase complex, chlorogenic acid, catechins, procyanidin B2, low browning apple

Abstract. Enzymatic browning is one of the most important reactions that occur in fruits and vegetables, usually resulting in negative effects on color, taste, flavor, and nutritional value. The reaction is a consequence of phenolic compounds' oxidation by polyphenol oxidase (PPO), which triggers the generation of dark pigments. This is particularly relevant for apples, which are rich in polyphenols and highly susceptible to enzymatic browning. The objective of the present work was to quantify enzymatic browning and PPO activity and identify and quantify target polyphenols in apple [Malus $\times$ sylvestris (L.) Mill. var. domestica (Borkh.) Mansf.] pulp in the cultivars (cvs.) Aori27, Elstar, Fuji, and Mellow at three fruit developmental stages (FDS). The enzymatic browning was quantified by tristimulus colorimetry; PPO activity was quantified by an enzymesubstrate spectrophotometric assay; phenolic compounds were determined and quantified by reverse-phase high-performance liquid chromatography-ultraviolet/visible-mass spectrometry. Enzymatic browning showed significant difference among cvs. and FDSs and interaction between both factors. PPO activity showed significant difference among cultivars and FDSs. A significant difference was evidenced for polyphenol content among cultivars and FDSs with interaction between both factors. Chlorogenic acid was the major phenolic compound in 'Aori27' and 'Mellow'. In 'Fuji', chlorogenic acid and (-)-epicatechin were the major phenolics and in 'Elstar' (-)-epicatechin and procyanidin B2 were the major phenolics at different FDSs. The enzymatic browning showed high correlation to polyphenol content in all cultivars and high correlation was observed between browning and PPO activity in 'Aori27' and 'Elstar'. The magnitude of the correlation between browning and polyphenols and PPO activity is genotype-specific. At the commercial harvest, 'Fuji' showed the highest polyphenol content and 'Aori27' showed the lowest level for enzymatic browning. Chemical names used: 3-(3,4-dihydroxycinnamoyl) quinic acid (chlorogenic acid), (-)-cis-3,3',4',5,7-pentahydroxyflavane (epicatechin), and cis,cis" ${ }^{\prime \prime}, 8^{\prime \prime}$-Bi $\left(3,3^{\prime}, 4^{\prime}, 5,7-\right.$ pentahydroxyflavane) (procyanidin B2).

Apples (Malus $\times$ sylvestris var. domestica) are an important source of polyphenols (phenolic compounds) in the human diet (Hertog et al., 1992) and a classic example of fruit susceptibility to enzymatic browning, which is a major problem for the fruit processing industry (Coseteng and Lee, 1987).

Phenolic compounds are partially responsible for color, astringency, bitterness, flavor, and nutritional qualities in fruits and vegeta- bles (Macheix et al., 1990). In fruits, they are the most important group of secondary metabolites, varying widely in quantity and quality among different species (Macheix et al., 1990).

In plant cells, phenolic compounds are located in the vacuoles, whereas polyphenol oxidase (EC 1.10.3.1, PPO) is located in plastids. Damaged areas in cells allow the contact between PPO and phenolic compounds, triggering the reaction known as enzymatic browning (Vaughn and Duke, 1984).

Several studies have shown that the enzymatic browning in apple pulp is associated with polyphenol content (Murata et al., 1995a; Vamos-Vigyazo and Gajzago, 1976) and/or PPO activity (Coseteng and Lee, 1987; Walker, 1962). The enzymatic browning is a consequence of the oxidation of polyphenols to their corresponding quinones by PPO. These quinones are then polymerized with other quinones or phenolics, originating brown pigments (Murata et al., 1995a).

The control of the enzymatic browning is of great importance to the horticulture industry, because this reaction occurs in many fruits and vegetables, often negatively affecting the attributes of color, taste, flavor, and nutritional value. It is estimated that more than $50 \%$ of fruit market losses are a result of enzymatic browning (Whitaker and Lee, 1995).

Cultivar selection targeted for various consumption purposes is currently receiving attention in apple breeding programs around the world (Laurens, 1999). As a result of the high antioxidant activity of polyphenols, which have shown beneficial effects for human health (Heim et al., 2002), varieties with high polyphenol content are interesting for fresh consumption, whereas low enzymatic browning potential is relevant for apple processing (Podsedek et al., 2000) as a way to avoid the formation of off-flavor and maintain the original pulp color and nutritional value for a longer period of time (Murata et al., 1995a; Podsedek et al., 2000).

The objective of the present work was to quantify enzymatic browning, PPO activity, and six target phenolic compounds \{chlorogenic acid, [-]-catechin [(-)-trans-3,3', 4', 5,7-pentahydroxyflavane], [-]-epicatechin, [-]-epicatechin gallate [(-)-cis-3,3', 4' , 5,7-pentahydroxyflavane-3gallate], [-]-epigallocatechin gallate [(-)-cis$3,3^{\prime}, 4^{\prime}, 5,5^{\prime}, 7$-hexahydroxy-flavane-3-gallate], and procyanidin B2\} in the pulp of four apple cultivars during fruit development.

\section{Materials and Methods}

All laboratory procedures took place at the Aomori Apple Institute Breeding Department Laboratory, Japan, with exception of the spectrophotometrical analysis, which was carried out at the Cultivation Department Laboratory of the same institution. Acetone, chloroform, acetonitrile, and formic acid were purchased from Wako Pure Chemical Industries Ltd. (Japan). All chemicals were of high-performance liquid chromatography grade.

\section{Fruit source}

Fruits were collected from apple trees (Malus Xsylvestris var. domestica), cvs. Aori27, Elstar, Fuji, and Mellow grafted on M26 EMLA rootstock, cultivated at the Aomori Apple Institute. Apples were collected at three fruit developmental stages (FDS) according to the maturation cycle of each cultivar. Immature fruits [initial fruit developmental stage (IFDS)] were collected 
2 months after pollination (middle July 2008). Fruits at intermediary developmental stage (MFDS) were collected mid-August ('Elstar'), late August ('Aori27'), and midSeptember ('Fuji' and 'Mellow'). The last fruit collection took place at commercial harvest time [final fruit developmental stage (FFDS)] of 'Aori27' (mid-October), 'Elstar' (mid-September), and 'Fuji' and 'Mellow' (early November). All samplings were carried out on the same tree for each cultivar at each FDS, collecting three fruits per cultivar per FDS. After collection, the fruits were stored in a cold chamber at $2{ }^{\circ} \mathrm{C}$ for $1 \mathrm{~d}$ and then used for analysis.

\section{Apple enzymatic browning quantification}

Enzymatic browning was quantified based on the grated pulp of fruits collected from each FDS. Three longitudinal slices were cut and peeled from each apple, and the core portion was discarded. The apple slices were then grated with a hand-grater (diameter of holes $0.5 \mathrm{~cm}$ ) on white trays, and three tristimulus colorimetric measurements were taken per fruit sample, the mean values being recorded. CIELab system parameters were applied, and values of $\mathrm{L}^{*}, \mathrm{a}^{*}$, and $\mathrm{b}^{*}$ were obtained immediately after the apple pulp was grated and $24 \mathrm{~h}$ later (times zero and 24 h) with a CR-300 colorimeter (Minolta, Japan) using D65 color space previously calibrated on a white calibration plate. The CIELab color difference formula $[\Delta \mathrm{E}=$ $\left.\left(\Delta \mathrm{L}^{2}+\Delta \mathrm{a}^{2}+\Delta \mathrm{b}^{2}\right)^{1 / 2}\right]$ (Comission Internationale de l'Eclairage, 1976) was used. Results were expressed as color difference units $(\Delta \mathrm{E})$ between two $\mathrm{L}^{*} \mathrm{a} * \mathrm{~b} *$ colors based on the values obtained at the two measurement times (zero and $24 \mathrm{~h}$ ).

\section{Apple polyphenol oxidase activity quantification}

PPO activity quantification was based on the method described by Murata et al. (1995a) with some modifications. For each fruit, three longitudinal slices (without the core portion) were cut, peeled, and chopped and $10 \mathrm{~g}$ of pulp was weighed. The pulp was homogenized with $30 \mathrm{~mL}$ of cold $100 \%$

\footnotetext{
Received for publication 22 Mar. 2010. Accepted for publication 1 June 2010.

This paper is a portion of a thesis submitted by Daniel Ferreira Holderbaum in fulfilling a Bachelor degree in Agronomic Engineering at the Federal University of Santa Catarina, Brazil.

This study was financed by the Aomori Prefectural Government, Japan, which also provided financial support to D. F. Holderbaum, during the Aomori Prefecture technical training exchange program of Aomori International Exchange Association. M.P. Guerra thanks the Brazilian National Research Council $(\mathrm{CNPq})$ for fellowship. We also thank Taciane Finatto, Nelson Jacomel, Jr., Lirio Luis Dal Vesco, Satoshi Kasai, Marcelo Maraschin, and Rubens Onofre Nodari for helpful suggestions

${ }^{1}$ To whom reprint requests should be addressed; e-mailmpguerra@cca.ufsc.br.
}

acetone at 15.000 RPM under ice cooling. The homogenate was then centrifuged at $5153 g_{\mathrm{n}}$ at $4{ }^{\circ} \mathrm{C}$ for $5 \mathrm{~min}$. The supernatant was filtered to a polypropylene tube and stored in a plastic foam box with ice. The residue was submitted to three more extractions with $20 \mathrm{~mL}$ of acetone $(80 \%, 80 \%$, and $100 \%$, respectively) under shaking (120 times/min) for $10 \mathrm{~min}$ followed by centrifugation, filtering, and storage of the supernatant. The combined filtered fraction was used as the phenolic compound extract for the polyphenol analysis. The residue was vacuum-filtered, freeze-dried, kept as an acetone powder on a polypropylene tube, and stored in a freezer at $-20^{\circ} \mathrm{C}$ until analysis. Acetone powder samples were weighed and $0.5 \mathrm{~g}$ was separated for the analytical procedure. PPO extraction was carried out with $40 \mathrm{~mL}$ of cold McIlvaine buffer $(0.1 \mathrm{M}$ citrate- $0.2 \mathrm{M}$ phosphate) $(\mathrm{pH} 5.0)$ on a homogenizer with a pestle for $3 \mathrm{~min}$. The homogenate was vacuum-filtered and then centrifuged at $6522 g_{n}$ for $30 \mathrm{~min}$ at $4{ }^{\circ} \mathrm{C}$. The supernatant was used as PPO extract, and its activity was quantified in a Shimadzu ultraviolet-1600 spectrophotometer (Shimadzu, Kyoto, Japan) at 325 $\mathrm{nm}$ according to the method described by Fujita and Tono (1988). The reaction solution consisted of $1.6 \mathrm{~mL}$ of PPO extract, $2.0 \mathrm{~mL}$ of deionized water, and $0.4 \mathrm{~mL}$ of chlorogenic acid $(1 \mathrm{~mm})$, being incubated at $30{ }^{\circ} \mathrm{C}$ in a water bath. Absorbance was measured at 3 and $8 \mathrm{~min}$ of reaction. An absorbance decrease of 0.01 per minute was considered 1 unit of PPO activity.

\section{Apple polyphenol determination and quantification}

Polyphenol extraction and extract purification. The polyphenol extracts consisted of filtrates obtained with the acetone powder preparation completed to $100 \mathrm{~mL}$ in a volumetric flask, separated into two aliquots of $50 \mathrm{~mL}$, and stored in a cold chamber at $2{ }^{\circ} \mathrm{C}$ in the absence of light until the purification procedure was conducted. Extracts (50 $\mathrm{mL}$ ) were concentrated in a vacuum evaporator under heating in a water bath at $40{ }^{\circ} \mathrm{C}$ for $30 \mathrm{~min}$. The concentrate was washed with $20 \mathrm{~mL}$ of ultra-pure water and transferred to a $200-\mathrm{mL}$ burette. Twenty milliliters of chloroform was added to the sample, and the biphasic system formed was submitted to vigorous hand agitation for $2 \mathrm{~min}$ at room temperature followed by removal of the chloroform. At last, the sample was completed to $50 \mathrm{~mL}$ with ultra-pure water, filtered in ADVANTEC No. 2 filter paper (Toyo Roshi Kaisha, Tokyo, Japan), placed on a plastic tube, and stored at $2{ }^{\circ} \mathrm{C}$ in the absence of light until analysis.

High-performance liquid chromatographymass spectrometry conditions. The reverse-phase high-performance liquid chromatographyultraviolet/visible-mass spectrometry (RPHPLC-UV/Vis-MS) analysis of phenolic compounds followed the recommendations of Hitachi Technical Data Series No. 77 with modifications. Purified extract aliquots were filtered in a hydrophilic disposable membrane of $0.20 \mu \mathrm{m}$ (DISMIC-25CS Cellulose-Acetate; Advantec Co., Ltd., Japan) into HPLC vials and then completed to $2 \mathrm{~mL}$ with ultra-pure water. The volume of each phenolic extract aliquot depended on the FDS, the proportion being 1:3, 1:1, and 1:0 (extract: water) at initial, intermediary, and final FDS, respectively.

RP-HPLC-UV/Vis-MS used the Hitachi M-8000 LC/3DQMS system (HITACHI, Tokyo, Japan) with the following configuration: M-8000 mass spectrometer using Sonic Spray Ionization in negative ion mode; Inertsil ODS-3 (5- $\mu \mathrm{m}$ particle size) $2.1 \times 150-\mathrm{mm}$ analytical column (GL Science, Tokyo, Japan) in a column oven at $40{ }^{\circ} \mathrm{C}$; L-7420 ultraviolet detector at $280-\mathrm{nm}$ wavelength; L-7100 pump; eluents formic acid $(0,1 \%)(\mathrm{A})$ and acetonitrile $(80 \%)(\mathrm{B})$; flow rate of 0.3 $\mathrm{mL} \cdot \mathrm{min}^{-1} ; 5 \mu \mathrm{L}$ of standards and samples were injected. The following gradient program was used: A) $100 \%$ to $90 \%$ from 0 to $3 \mathrm{~min} ; 90 \%$ to $75 \%$ from 3 to $30 \mathrm{~min} ; 75 \%$ to $0 \%$ from 30 to $35 \mathrm{~min} ; 0 \%$ from 35 to $40 \mathrm{~min}$; and $0 \%$ to $100 \%$ from $40.1 \mathrm{~min}$ to $65 \mathrm{~min}$; and B) $0 \%$ to $10 \%$ from 0 to $3 \mathrm{~min} ; 10 \%$ to $25 \%$ from 3 to $30 \mathrm{~min} ; 25 \%$ to $100 \%$ from 30 to $35 \mathrm{~min}$; $100 \%$ from 35 to $40 \mathrm{~min}$; and $0 \%$ from 40.1 to $65 \mathrm{~min}$. The M-8000 System Manager software (HITACHI) was used for the analysis.

Chlorogenic acid (CA) (95\% or greater), catechin (C) (98\% or greater), epicatechin (EC) $(97 \%)$ (Sigma-Aldrich, Germany), epicatechin gallate (ECG) ( $98 \%$ or greater), epigallocatechin gallate (EGCG) $(98 \%$ or greater) (Wako Pure Chemical Industries Ltd., Japan), and Procyanidin B2 (PRO) (99\%) (ChromaDex) were used. Standards consisted of a mixture of CA, C, EC, ECG, EGCG, and PRO with the proportion of $1: 1: 1: 1: 1: 1$. The concentration of each phenolic compound ranged from $6.66 \mathrm{mg} \cdot \mathrm{L}^{-1}$ to $33.33 \mathrm{mg} \cdot \mathrm{L}^{-1}$ on the calibration curve. Each compound was determined by its mass chromatogram and respective mass spectrum isolated from a Total Ion Chromatogram (TIC) and quantified as the correspondent peak area. Representative linear regression equations and correlation coefficients from the calibration curves are as follows: $\mathrm{y}=1.158 \times-0.4\left(r^{2}=\right.$ $0.9288)$ for $\mathrm{CA}, \mathrm{y}=1.682 \times-0.4\left(r^{2}=0.9129\right)$ for $\mathrm{C}, \mathrm{y}=2.758 \times-0.4\left(r^{2}=0.9971\right)$ for $\mathrm{EC}$, $\mathrm{y}=7.705 \times-0.5\left(r^{2}=0.9972\right)$ for $\mathrm{ECG}, \mathrm{y}=$ $1.257 \times-0.4\left(r^{2}=0.9969\right)$ for EGCG, and $\mathrm{y}=$ $1.842 \times-0.4\left(r^{2}=0.9642\right)$ for PRO.

\section{Statistical analysis}

Data were submitted to Bartlet variance homogeneity test, and when necessary data were transformed according to the SAS software recommendations (SAS Institute Inc., 2002). Analysis of variance was then performed and when significant differences were detected $(P<0.01)$, Student-NewmanKeuls multiple means comparison test (SNK) was carried out at the 5\% significance level (Steel et al., 1997). Additionally, the Pearson correlation test $(P<0.01$ and $P<0.05)$ was performed correlating the variable $\Delta \mathrm{E}$ (enzymatic browning - color difference) to polyphenol oxidase activity, phenolic compounds, 
Table 1. Apple pulp enzymatic browning ( $\Delta \mathrm{E}$ units - color difference between two CIELab colors, measured immediately and $24 \mathrm{~h}$ after apple pulp grating) and polyphenol oxidase activity (units $100 \mathrm{~g}^{-1}$ of fresh weight) observed in four apple cultivars (Aori27, Elstar, Fuji, and Mellow) at initial, intermediary, and final fruit developmental stages (IFDS, MFDS, and FFDS, respectively). ${ }^{\mathrm{z}}$

\begin{tabular}{|c|c|c|c|c|c|c|}
\hline \multirow[b]{2}{*}{ Cultivar } & \multicolumn{3}{|c|}{ Enzymatic browning ( $\Delta \mathrm{E}$ units) } & \multicolumn{3}{|c|}{ PPO activity (units $100 \mathrm{~g}^{-1} \mathrm{FW}$ ) } \\
\hline & IFDS & MFDS & FFDS & IFDS & MFDS & FFDS \\
\hline Aori27 & 39.8 a (a) \pm 3.2 & $22.1 \mathrm{~b}(\mathrm{~b}) \pm 0.9$ & $8.2 \mathrm{c}(\mathrm{c}) \pm 1.7$ & $540.1 \mathrm{~b}(\mathrm{a}) \pm 167.0$ & $220.5 \mathrm{c}(\mathrm{ab}) \pm 161.3$ & $69.2 \mathrm{~b}(\mathrm{~b}) \pm 60.2$ \\
\hline Elstar & $43.1 \mathrm{a}(\mathrm{a}) \pm 2.6$ & 30.9 a (b) \pm 1.9 & $24.4 \mathrm{~b}(\mathrm{c}) \pm 2.5$ & 2188 a (a) \pm 506.3 & $1561 \mathrm{ab}(\mathrm{a}) \pm 587.1$ & $1160.6 \mathrm{a}(\mathrm{a}) \pm 108.1$ \\
\hline Fuji & $38.4 \mathrm{a}(\mathrm{a}) \pm 1.3$ & $30.7 \mathrm{a}(\mathrm{b}) \pm 3.2$ & $32.7 \mathrm{a}(\mathrm{b}) \pm 4.5$ & 2199.9 a (a) \pm 757.7 & 1929.6 a (a) \pm 144.5 & 1307.9 a (a) \pm 291.4 \\
\hline $\begin{array}{l}\text { Mellow } \\
\text { CV \% }\end{array}$ & 42.9 a (a) \pm 1.8 & $\begin{array}{c}32.8 \mathrm{a}(\mathrm{b}) \pm 0.7 \\
3.72\end{array}$ & $33.4 \mathrm{a}(\mathrm{b}) \pm 0.7$ & $1370.7 \mathrm{ab}(\mathrm{a}) \pm 745.7$ & $\begin{array}{c}676.6 \mathrm{~b}(\mathrm{a}) \pm 107.7 \\
16.93\end{array}$ & 568.9 a (a) \pm 174.1 \\
\hline
\end{tabular}

${ }^{\mathrm{z}}$ Means followed by different letters in fruit developmental stage and means followed by different letters between parentheses in cultivar differ significantly $(P<$ 0.01 ) by the Student-Newman-Keuls multiple means separation test. Data shown as mean $\pm \mathrm{SD} ; \mathrm{n}=3$.

and major phenolic compound. Statistical analysis was carried out by means of the SAS software (SAS Institute Inc., 2002).

\section{Results}

Apple enzymatic browning quantification. The analysis of variance for the variable $\Delta \mathrm{E}$ (color difference between two $\mathrm{L}^{*} \mathrm{a} * \mathrm{~b} *$ colors, measured at times 0 and $24 \mathrm{~h}$ ) showed significant differences $(P<0.01)$ among cultivars and FDSs and a significant interaction between both factors was detected. According to the SNK multiple means comparison test, all cultivars showed a decrease on $\Delta \mathrm{E}$ during fruit maturation. A clear difference was observed between cultivars with 'Aori27' and 'Elstar' evidencing a trend to a continuous decrease of $\Delta \mathrm{E}$ values. 'Fuji' and 'Mellow' showed a decrease at early fruit development and subsequently kept a constant level (Table 1). At the IFDS, no significant difference was observed for $\Delta \mathrm{E}$ values among the four cultivars. At the MFDS, 'Aori27' presented significantly lower mean value of $\Delta \mathrm{E}$ than the other three cultivars. At the commercial harvest time, 'Fuji' and 'Mellow' showed the highest $\Delta \mathrm{E}$ values followed by 'Elstar' and 'Aori27', the last showing significantly lower color difference than all other cultivars, evidencing a lower degree of pulp enzymatic browning. The pulp color of each cultivar in every FDS, $24 \mathrm{~h}$ after grating, is illustrated in Figure 1A-L.

Apple polyphenol oxidase activity quantification. Significant differences for PPO activity were observed among cultivars and FDSs (Table 1). At the IFDS, 'Fuji' and 'Elstar' presented the highest values followed by 'Mellow' and 'Aori27', the last showing a significantly lower value than 'Fuji' and 'Elstar'. At the MFDS, 'Fuji' and 'Elstar' presented the highest mean values for PPO activity followed by 'Mellow', which presented similar values to those observed for 'Elstar' but different from those recorded for 'Fuji'. 'Aori27' presented the lowest mean value among all cultivars at the MFDS. At the commercial harvest time (FFDS), 'Aori27' showed the lowest PPO activity among all cultivars, and no statistical differences were observed among 'Elstar', 'Fuji', and 'Mellow' (Table 1). 'Elstar', 'Fuji', and 'Mellow' did not show significant differences for PPO activity during fruit development, whereas 'Aori27' showed a significant decrease along

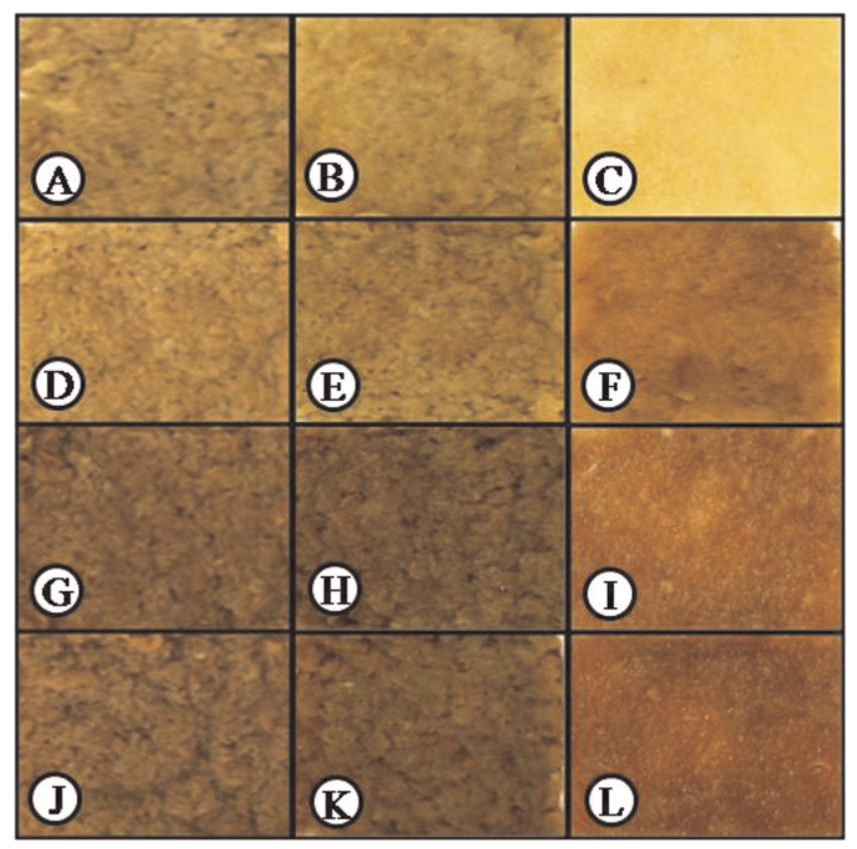

Fig. 1. Detail of apple pulp's color of four cultivars at initial, intermediary, and final fruit developmental stages (IFDS, MFDS, and FFDS, respectively) $24 \mathrm{~h}$ after grating. 'Aori27': IFDS (A), MFDS (B), and FFDS (C). 'Elstar': IFDS (D), MFDS (E), and FFDS (F). 'Fuji': IFDS (G), MFDS (H), and FFDS (I). 'Mellow': IFDS (J), MFDS (K), and FFDS (L).

fruit maturation with the values recorded at the FFDS showing lower mean than the values recorded at the IFDS (Table 1).

Apple polyphenol determination and quantification. To determine each analyzed compound, its chemical structure, retention time, and the $m / \mathrm{z}$ ratio of the molecular ion were assessed (Table 2). Then, each compound was quantified as its correspondent peak area on a TIC (Fig. 2). The quantification of polyphenols evidenced significant difference among cultivars and FDSs as well as significant interaction between both factors for chlorogenic acid, epicatechin, procyanidin B2, and total polyphenols (chlorogenic acid + epicatechin + procyanidin B2). The multiple means comparison for the variable phenolic compound showed the differences obtained for each compound in the four cultivars at the three FDSs (Table 3). Catechin, epicatechin gallate, and epigallocatechin gallate were identified by their respective mass spectra and tentatively quantified in the pulp of the four cultivars. Low concentrations (less than 0.05 $\mathrm{mg} / 100 \mathrm{~g}$ fresh weight) were found for these compounds associated with a wide range of values in the samples. Thus, it was not possible to accurately determine their contents.

Chlorogenic acid was identified as the major phenolic compound in 'Aori27' and 'Mellow' at all FDSs. In 'Fuji', chlorogenic acid and epicatechin were identified as major phenolic compounds at the IFDS, whereas chlorogenic was the major phenolic on the subsequent FDSs. In 'Elstar', epicatechin was identified as the major phenolic at both IFDS and MFDS, and procyanidin was the major polyphenol at the FFDS. 'Fuji' showed the highest levels of chlorogenic acid at all FDSs, and the lowest content was observed in immature fruits of 'Elstar'. The highest content of epicatechin was recorded on 'Fuji' immature fruits. At the MFDS and at the commercial harvest time, 'Elstar' showed the highest contents of epicatechin. At the MFDS and FFDS, epicatechin was not observed in 'Aori27'. 'Fuji' showed the highest procyanidin B2 levels at the IFDS and MFDS. At the FFDS, 'Elstar' showed the highest content of procyanidin B2. Only traces of procyanidin B2 were found in 'Aori27' at the FFDS. In immature fruits of 'Aori27' and 'Mellow', procyanidin B2 was 
Table 2. Chemical structure, retention time (RT), and $\mathrm{m} / z$ ratio of the molecular ion $\left[\mathrm{M}^{+}\right]$of chlorogenic acid, catechin, epicatechin, epicatechin gallate, epigallocatechin gallate, and procyanidin B2 observed through high-performance liquid chromatography-mass spectrometry analysis.

Compound
Chlorogenic acid

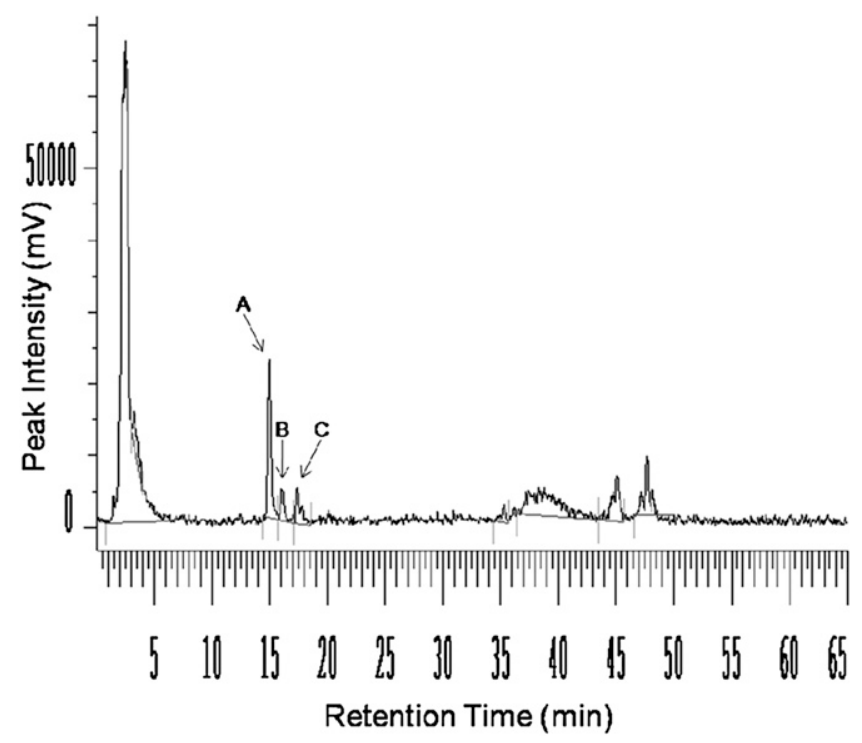

Fig. 2. Example of a Total Ion Chromatogram (TIC). 'Mellow', intermediary fruit developmental stage. (A) Chlorogenic acid; (B) epicatechin; (C) procyanidin B2.

not observed. In all FDSs, 'Fuji' presented the highest phenolic concentration (chlorogenic acid + epicatechin + procyanidin B2) followed by 'Mellow', 'Elstar', and 'Aori27' (Table 3).

Correlations. Significant positive correlations $(P<0.01)$ were found between $\Delta \mathrm{E}$ (color difference) values and the respective PPO activity values for 'Aori27' and 'Elstar' $(R=$ 0.83 and $R=0.78$, respectively), but not for 'Fuji' and 'Mellow'. The $\Delta \mathrm{E}$ values and the respective phenolic concentrations determined by RP-HPLC-ultraviolet/Vis-MS showed significant positive correlations $(P<0.01)$ for all cultivars. 'Aori27' and 'Mellow' revealed very high correlation $(R=0.91$ and $R=0.93$, respectively), 'Elstar' showed high correlation $(R=0.80)$, and the same was observed in 'Fuji' $(R=0.71, P<0.05)$. The $\Delta \mathrm{E}$ values were also correlated to the values obtained for the major phenolics in each cultivar. For 'Aori27' and 'Mellow', a very high positive correlation was found between chlorogenic acid content and
$\Delta \mathrm{E}(R=0.92$ and $R=0.96$, respectively). For 'Elstar', a very high positive correlation was found between the epicatechin content and $\Delta \mathrm{E}$ $(R=0.96)$, whereas procyanidin $\mathrm{B} 2$ did not show significant correlation to $\Delta \mathrm{E}$. For 'Fuji', high positive correlations $(P<0.05)$ were found between $\Delta \mathrm{E}$ and chlorogenic acid and epicatechin $(R=0.72$ and $R=0.88$, respectively).

\section{Discussion}

Varietal differences regarding the susceptibility to enzymatic browning were evidenced among the four apple cultivars as previously reported (Coseteng and Lee, 1987; Murata et al., 1995a). The enzymatic browning dynamics observed during fruit development in all cultivars is coherent with the results obtained by Coseteng and Lee (1987), Murata et al. (1995b), and Valentines et al. (2005), which showed that the browning potential is influenced by FDS, decreasing according to

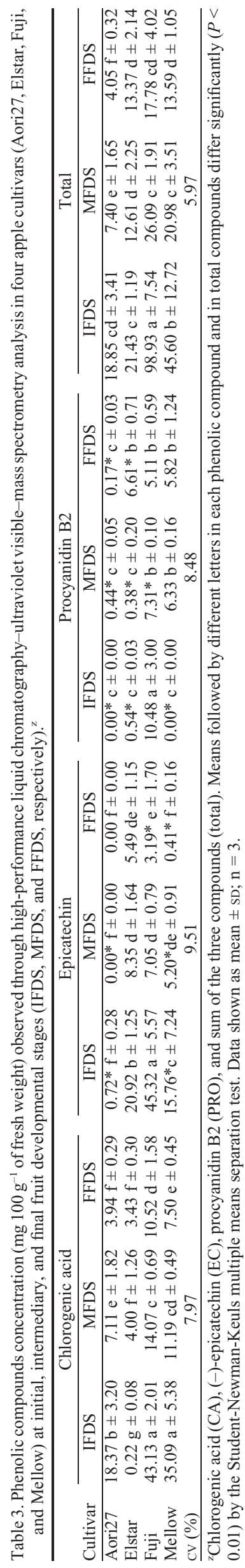


the progress in fruit ripening. In this study, 'Aori27' showed the lowest browning at harvest time, the color difference being hardly perceptible. The other three cultivars showed significantly higher browning than 'Aori27' at harvest time, the color difference being easily perceptible. However, in a separate analysis of 'Aori27' browning potential, it was observed that the age of the tree and/or the rootstock used apparently affected the pulp's browning potential (data not shown).

At commercial harvest time, 'Elstar' showed lower mean $\Delta \mathrm{E}$ value than 'Fuji' and 'Mellow', although total phenolic content and PPO activity showed no significant differences among these three cultivars at the FFDS. However, 'Elstar' was the only cultivar in which epicatechin and procyanidin B2 were identified as the major phenolic compounds, whereas this cultivar showed relatively low levels of chlorogenic acid. This may help to explain the lower browning of 'Elstar' compared with 'Fuji' and 'Mellow' considering that differences in color formation by enzymatic browning can be a consequence of oxidation of different phenolic compounds (Murata et al., 1995a).

Similar to what was reported by Podsedek et al. (2000) regarding apples, varietal differences were detected for PPO activity, with 'Aori27' showing lower PPO activity than all the other cultivars at the FFDS, besides being the only cultivar in which significant differences were observed for PPO activity at different FDSs. Nevertheless, the PPO activity values obtained for 'Elstar', 'Fuji', and 'Mellow' at the three distinct FDSs are in accordance with the results obtained by Valentines et al. (2005), which observed no significant difference for PPO activity in immature and mature fruits of 'Golden Delicious' apple.

Significant positive correlations were found between PPO activity and enzymatic browning $(\Delta \mathrm{E})$ in the pulp of 'Aori27' and 'Elstar', which was not observed for 'Fuji' and 'Mellow'. Murata et al. (1995a) found a positive correlation between polyphenol content and enzymatic browning, but not between PPO activity and enzymatic browning, for a group of apple cultivars, including 'Fuji'. Coseteng and Lee (1987) did not find a correlation between polyphenols or PPO activity and enzymatic browning in seven apple cultivars analyzed as a whole. However, the same authors noted that the seven cultivars could be separated into two groups with the enzymatic browning showing good correlation to polyphenol content in one and to PPO activity in the other. The results obtained in the present study reinforce the notion that the dynamics of PPO activity during fruit development is a genotype-dependent variable in apples.

In general, a decrease in the phenolic concentration was observed along fruit maturation in the present work. The same was observed in apples by other authors (Coseteng and Lee, 1987; Valentines et al., 2005). Chlorogenic acid and epicatechin had been reported as the major phenolics in several apple cultivars (Coseteng and Lee, 1987; Murata et al., 1995a; Podsedek et al., 2000;
Walker, 1962). Murata et al. (1995a) identified chlorogenic acid as the major phenolic in 'Fuji'. In the present study, chlorogenic acid was identified as the major phenolic in 'Aori27', 'Fuji', and 'Mellow'. In 'Elstar', epicatechin was the major phenolic. In addition, epicatechin was also a major polyphenol at the IFDS of 'Fuji', whereas in 'Elstar', procyanidin B2 showed the highest content at commercial harvest.

The significant positive correlations found in the present work between total phenolic compounds (chlorogenic acid + epicatechin + procyanidin $\mathrm{B} 2$ ) and the enzymatic browning in all cultivars evidenced the influence of such compounds on the browning potential in these apple cultivars. These results are in accordance with other findings in several apple cultivars (Coseteng and Lee, 1987; Murata et al., 1995a).

Significant positive correlations were also found between the content of major phenolics and $\Delta \mathrm{E}$, because the major phenolics followed the general trend of decrease on the total phenolic content along fruit development in all cultivars. These results contrast to those obtained by Coseteng and Lee (1987) in different apple cultivars, in which no relation was verified between any particular phenolic compound content and enzymatic browning.

It is worth noting that genetically modified apple cultivars are currently being developed through antisense DNA techniques to obtain varieties with low browning potential (e.g., Cao et al., 2004; Murata et al., 2000, 2001), whereas there is evidence of apple germplasm with low browning potential already available.

In conclusion, under the scope of this study, the results showed that among the studied cultivars, 'Fuji' is the most suitable for fresh consumption as a result of its higher phenolic content at commercial harvest time, and 'Aori27' is the best for fruit processing as a result of its low enzymatic browning (associated to the lowest PPO activity and the lowest polyphenol content). The enzymatic browning potential in apples depends on the fruit's developmental stage, being predominantly influenced by the polyphenol content and the polyphenol oxidase activity, although other factors such as the quality and relative proportion of polyphenols can also be influential. The magnitude of the relation between enzymatic browning and polyphenol content and polyphenol oxidase activity is genotype-specific. These results are relevant for the apple industry and consequently for apple breeding programs. Our results should help to establish new criteria for the selection of apple cultivars, emphasizing the importance of apple germplasm to the control of enzymatic browning.

\section{Literature Cited}

Cao, Y.H., Z. Zhang, Q.H. Yao, R.H. Peng, A.S. Xiong, and X. Li. 2004. Suppression of apple polyphenol oxidase by double-stranded RNA (RNAi). Acta Biol. Exper. Sinic. 37:487-493 [in Chinese].

Comission Internationale de l'Eclairage. 1976 Recommendations on uniform color spaces:
Color-difference equations; Psychometric color terms. CIE Publication 15. Bureau Central de la CIE, Paris, France.

Coseteng, M.Y. and C.Y. Lee. 1987. Changes in apple polyphenoloxidase and polyphenol concentrations in relation to degree of browning. J. Food Sci. 52:985-989.

Fujita, S. and T. Tono. 1988. Purification and some properties of polyphenoloxidase in eggplant (Solanum melongena). J. Sci. Food Agr. 46: 115-123.

Heim, K.E., A.R. Tagliaferro, and D.J. Bobilya. 2002. Flavonoid antioxidants: Chemistry, metabolism and structure-activity relationships. J. Nutr. Biochem. 13:572-584.

Hertog, M.G., P.C.H. Hollman, and M.B. Katan. 1992. Content of potentially anticarcinogenic flavonoids of 28 vegetables and 9 fruits commonly consumed in The Netherlands. J. Agr. Food Chem. 40:2379-2383.

Laurens, F. 1999. Review of the current apple breeding programmes in the world: Objectives for scion cultivar improvement. In: Tobutt, K.R. and F.H. Alston (eds.). Proc. Eucarpia Symp. Fruit Breed. Genet. Acta Hort. 484:163-170.

Macheix, J.J., A. Fleuriet, and J. Billot. 1990. Fruit phenolics. CRC Press, Boca Raton, FL.

Murata, M., M. Haruta, N. Murai, N. Tanikawa, M. Nishimura, S. Homma, and Y. Itoh. 2000. Transgenic apple (Malus $\times$ domestica) shoot showing low browning potential. J. Agr. Food Chem. 48:5243-5248.

Murata, M., M. Nishimura, N. Murai, M. Haruta, S. Homma, and Y. Itoh. 2001. A transgenic apple callus showing reduced polyphenol oxidase activity and lower browning potential. Biosci. Biotechnol. Biochem. 65:383-388.

Murata, M., I. Noda, and S. Homma. 1995a. Enzymatic browning of apples on the market: Relationship between browning, polyphenol content, and polyphenol oxidase. Nipon Shokuhin Kagaku Kogaku Kaishi 42:820-826 [in Japanese].

Murata, M., M. Tsurutani, M. Tomita, S. Homma, and K. Kaneko. 1995b. Relationship between apple ripening and browning: Changes in polyphenol content and polyphenol oxidase. J. Agr. Food Chem. 43:1115-1121.

Podsedek, A., J. Wilska-Jeszka, B. Anders, and J. Markowski. 2000. Compositional characterization of some apple varieties. Eur. Food Res. Technol. 210:268-272.

SAS Institute Inc. 2002. Version 8.0-Getting started with the SAS learning edition. SAS Institute Inc., Cary, NC.

Steel, G.D.R., J.H. Torrie, and D.A. Dickey. 1997. Principles and procedures of statistics: A biometrical approach. 3rd Ed. McGraw-Hill, New York, NY.

Valentines, M.C., R. Vilaplana, R. Torres, J. Usall, and C. Larrigaudière. 2005. Specific roles of enzymatic browning and lignification in apple disease resistance. Postharvest Biol. Technol. 36:227-234.

Vamos-Vigyazo, L. and I. Gajzago. 1976. Studies on the enzymatic browning and the polyphenolpolyphenol oxidase complex of apple cultivars. Confructa. 21:24-31.

Vaughn, K.C. and S.O. Duke. 1984. Function of polyphenol oxidase in higher plants. Physiol. Plant. 60:106-112.

Walker, J.R.L. 1962. Studies on the enzymatic browning of apple fruit. N. Z. J. Sci. 5:316324.

Whitaker, J.R. and C.Y. Lee. 1995. Recent advances in chemistry of enzymatic browning, p. 2-7. In: Lee, C.Y. and J.R. Whitaker (eds.). Enzymatic browning and its prevention. Amer. Chem. Soc. Symp. Ser. 600, Washington, DC. 